\title{
Limited Dorsal Myeloschisis and Congenital Dermal Sinus: Comparison of Clinical and MR Imaging Features
}

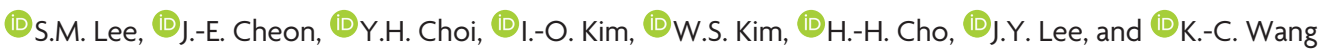

\begin{abstract}
BACKGROUND AND PURPOSE: While limited dorsal myeloschisis is a distinctive form of spinal dysraphism, it may be confused with congenital dermal sinus. The aim of this study was to describe clinical and MR imaging findings of limited dorsal myeloschisis that can distinguish it from congenital dermal sinus.
\end{abstract}

MATERIALS AND METHODS: We retrospectively reviewed the clinical and MR imaging findings of 12 patients with limited dorsal myeloschisis and 10 patients with congenital dermal sinus. Skin abnormalities, neurologic deficits, and infectious complication were evaluated on the basis of clinical information. We evaluated the following MR imaging features: visibility of the tract along the intrathecal course, attachment site of the tract, level of the conus medullaris, shape of the spinal cord, and presence of intradural lesions such as dermoid/ epidermoid tumors.

RESULTS: A crater covered with pale epithelium was the most common skin lesion in limited dorsal myeloschisis (10/12, $83 \%)$. Infectious complications were common in congenital dermal sinus $(6 / 10,60 \%)$, whereas none were found in limited dorsal myeloschisis $(P=.003)$. The following MR imaging findings were significantly different between the 2 groups $(P<.05)$ : 1) higher visibility of the intrathecal tract in limited dorsal myeloschisis $(10 / 12,83 \%)$ versus in congenital dermal sinus $(1 / 10,10 \%), 2)$ the tract attached to the cord in limited dorsal myeloschisis $(12 / 12,100 \%)$ versus various tract attachments in congenital dermal sinus, 3) dorsal tenting of the cord in limited dorsal myeloschisis $(10 / 12,83 \%)$ versus in congenital dermal sinus $(1 / 10,10 \%)$, and 4$)$ the presence of dermoid/epidermoid tumors in congenital dermal sinus $(6 / 10,60 \%)$ versus none in limited dorsal myeloschisis.

CONCLUSIONS: Limited dorsal myeloschisis has distinct MR imaging features: a visible intrathecal tract with dorsal tenting of the cord at the tract-cord union. Limited dorsal myeloschisis was not associated with infection and dermoid/epidermoid tumors.

ABBREVIATIONS: $C D S=$ congenital dermal sinus; $L D M=$ limited dorsal myeloschisis

$\mathbf{L}^{\mathrm{i}}$ imited dorsal myeloschisis (LDM) is a distinct form of spinal dysraphism characterized by 2 constant features: a focal "closed" midline skin defect and a fibroneural tract connecting the skin lesion to the underlying spinal cord. ${ }^{1,2}$ Histologically, its tract is composed of attenuated mesenchymal (mainly fibrous) tissue and neural elements without an epithelial lining. ${ }^{1-4}$ Because LDM has features similar to those in congenital dermal sinus

Received May 9, 2016; accepted after revision August 15.

From the Departments of Radiology (S.M.L., J.-E.C., Y.H.C., I.-O.K., W.S.K., H.-H.C.), Anatomy (J.Y.L.), and Neurosurgery, Division of Pediatric Neurosurgery (J.Y.L., K.-C.W.), Seoul National University College of Medicine, Seoul, Republic of Korea; Department of Radiology (S.M.L.), Kyungpook National University Medical Center, Daegu, Korea; and Department of Radiology (H.-H.C.), Ewha Womans University Mokdong Hospital, Seoul, Republic of Korea.

Please address correspondence to Jung-Eun Cheon, MD, Department of Radiology, Seoul National University College of Medicine, 101 Daehak-ro, Jongno-gu, Seoul 110-769, Republic of Korea; e-mail: cheonje@snu.ac.kr

http://dx.doi.org/10.3174/ajnr.A4958
(CDS) showing a skin dimple with an associated tract extending from the skin lesion to the intraspinal space, it may be confused with CDS and has been referred to as a "dermal sinus-like stalk" or "pseudodermal sinus tract." $1-5$

Despite the resemblance between the 2 disease entities, LDM has different clinical importances compared with CDS. LDM has a closed skin defect and a solid tract without a lumen; thus, the possibility of infectious complications is extremely low. ${ }^{5}$ The clinical importance of LDM is related to neurologic deficits resulting from spinal cord tethering. ${ }^{1,5}$ By contrast, a tract of CDS with a lumen communicating with a cutaneous opening is the entry route for pathogens, consequentially leading to devastating infectious complications such as intraspinal abscess or meningitis. ${ }^{6,7}$ CDS requires urgent surgical removal of the tract even in asymptomatic patients to prevent potential intraspinal infection, whereas surgical intervention can be delayed in LDM to avoid complications in the neonate period. ${ }^{1,8}$ 
To determine the appropriate treatment strategies, one must distinguish LDM-which still is not a familiar entity-from CDS preoperatively.

Pang et $\mathrm{al}^{1,2}$ have reported that many cases of LDM have been misreported as CDS, despite different clinicopathologic characteristics. Furthermore, some authors have suggested that it is difficult to differentiate these 2 entities by using clinical and radiologic examinations because the entities share neuroimaging and cutaneous findings. ${ }^{3,4}$ To our knowledge, however, there have been no published reports regarding the comparison of the radiologic findings in LDM and CDS. The aim of this study was to describe neuroimaging findings of LDM that can distinguish it from CDS.

\section{MATERIALS AND METHODS \\ Patients}

The institutional review board of Seoul National University Hospital approved this study and waived the requirements for informed consent. Retrospective review of the operative record data base of all patients who underwent an operation for congenital spinal dysraphism by a pediatric neurosurgeon (K-C.W.) from January 2010 to March 2014 was performed to identify subjects. The patients with closed spinal dysraphism without a subcutaneous mass characterized by midline skin lesions and an associated tract connecting the skin lesion to the focal area of the intraspinal space were classified into LDM and CDS groups on the basis of the operative and histopathologic findings. ${ }^{1,2,4,9-11}$ The diagnostic criteria of LDM were as follows: 1) dural outpouching ensheathing the tract identified ontracts.

Information regarding demographic variables such as age, sex, mode of presentation, symptoms prompting neurosurgical referral, initial neurologic and physical examination findings, preoperative radiologic evaluation, urologic study, and operative findings was collected. Skin abnormalities, neurologic deficits, and infectious complications were evaluated on the basis of clinical information.

\section{Imaging Analysis}

All patients underwent preoperative lumbosacral MR imaging. MR images were acquired in both sagittal and axial planes on a 1.5T MR imaging unit. The MR image parameters were as follows: unenhanced T1-weighted (TR/TE $=500-610 / 10-12 \mathrm{~ms}$ ), T2weighted $(\mathrm{TR} / \mathrm{TE}=3000-3500 / 93-99 \mathrm{~ms})$ turbo spin-echo, and postcontrast T1-weighted images (11 examinations). Other parameters included section thickness $=3 \mathrm{~mm}$ (sagittal), $6 \mathrm{~mm}$ (axial); intersection gap $=0.3 \mathrm{~mm}$ (sagittal), $3 \mathrm{~mm}$ (axial); acquisition matrix $=320 \times 224-256($ sagittal $), 320 \times 182-205($ axial $)$; and FOV $=18-20 \times 18-20 \mathrm{~cm}$ (sagittal), $8-10 \times 8-10 \mathrm{~cm}$ (axial).

The MR images, without accompanying clinical or pathologic information, were retrospectively reviewed in consensus by 2 pediatric imaging radiologists with 11 and 6 years of experience. The MR images were assessed for the following features: 1) visibility of the tract along its subcutaneous and intrathecal course, 2) attachment site of the tract, 3) the level of the conus medullaris, 4) change in the spinal cord shape, and 5) presence of an associated intradural lesion (abscess, dermoid, or epidermoid tumor or an- other dysraphia malformation). The MR imaging findings were compared with operational and histopathologic findings. The visibility of the tract was classified into 3 types depending on the traceability of the tract on MR images based on the operative finding as the reference standard: entirely visible, round tract separate from the filum terminale or nerve roots completely traceable in its entire course; partially visible, portions of the tract detected even though the entire course was not traceable; and poorly visible, no discernable tract demonstrated along its course. The level of the conus medullaris was considered normal when it terminated at or above the L2-3 intervertebral disc level. A change in the shape of the spinal cord was assessed for dorsal tenting at the level of tract-cord union. Dorsal tenting of the spinal cord was defined as follows: The cord shape appears to be ovoid (disproportionate increase in the anteroposterior-totransverse diameter relative to the upper and lower segments of the spinal cord) rather than round on axial images and/or to be tethered dorsally on sagittal images at the level of tract-cord union (Fig 1).

\section{Statistical Analysis}

The Fisher exact test was used to compare the male/female ratio, clinical features, and MR imaging findings between the LDM and CDS groups. The Mann-Whitney $U$ test was used to compare the ages of the 2 groups. A $P$ value $<.05$ was considered statistically significant. The data analyses were performed with the commercially available statistical software SPSS, Version 12 (IBM, Armonk, New York).

\section{RESULTS}

\section{Clinical Findings}

Twenty-two patients with surgically and histopathologically confirmed LDM $(n=12)$ and CDS $(n=10)$ were included in our study. Age at admission ranged from day of life 15 to 47 months of age (median age at presentation, 4 months; male/female ratio, 2:10) in patients with LDM. In patients with CDS, the age at admission ranged from day of life 7 to 34 months (median age at presentation, 11.5 months; male/female ratio, 6:4). There were no significant statistical differences in age at admission $(P=.207)$ and in male/female ratio $(P=.074)$.

In patients with LDM, the most common reason prompting a patient's referral was skin findings (11 patients, 92\%). Whereas the most common reason prompting a patient's referral in patients with CDS was infection ( 6 patients, $60 \%$ ) or skin findings (5 patients). In LDM, the most common skin lesion was a skincovered dimple that appeared as a sunken crater covered with pearly pale epithelium $(10 / 12,83 \%)$ (Fig 1). The remainder showed a pinpoint pit $(2 / 12,17 \%)$ (Fig 2). In CDS, all patients had a pinpoint pit $(10 / 10,100 \%)(P<.001)$. The accompanying skin lesions were as follows: a crater surrounded by a capillary hemangioma $(n=5)$ and hairs emanating from the crater $(n=1)$ in LDM; and hemangioma $(n=4)$ and hypertrichosis $(n=1)$ in CDS.

The prevalence of infectious complications was higher in the CDS group than the LDM group $(P=.003)$. None of the patients with LDM had infectious complications, whereas 6 of 

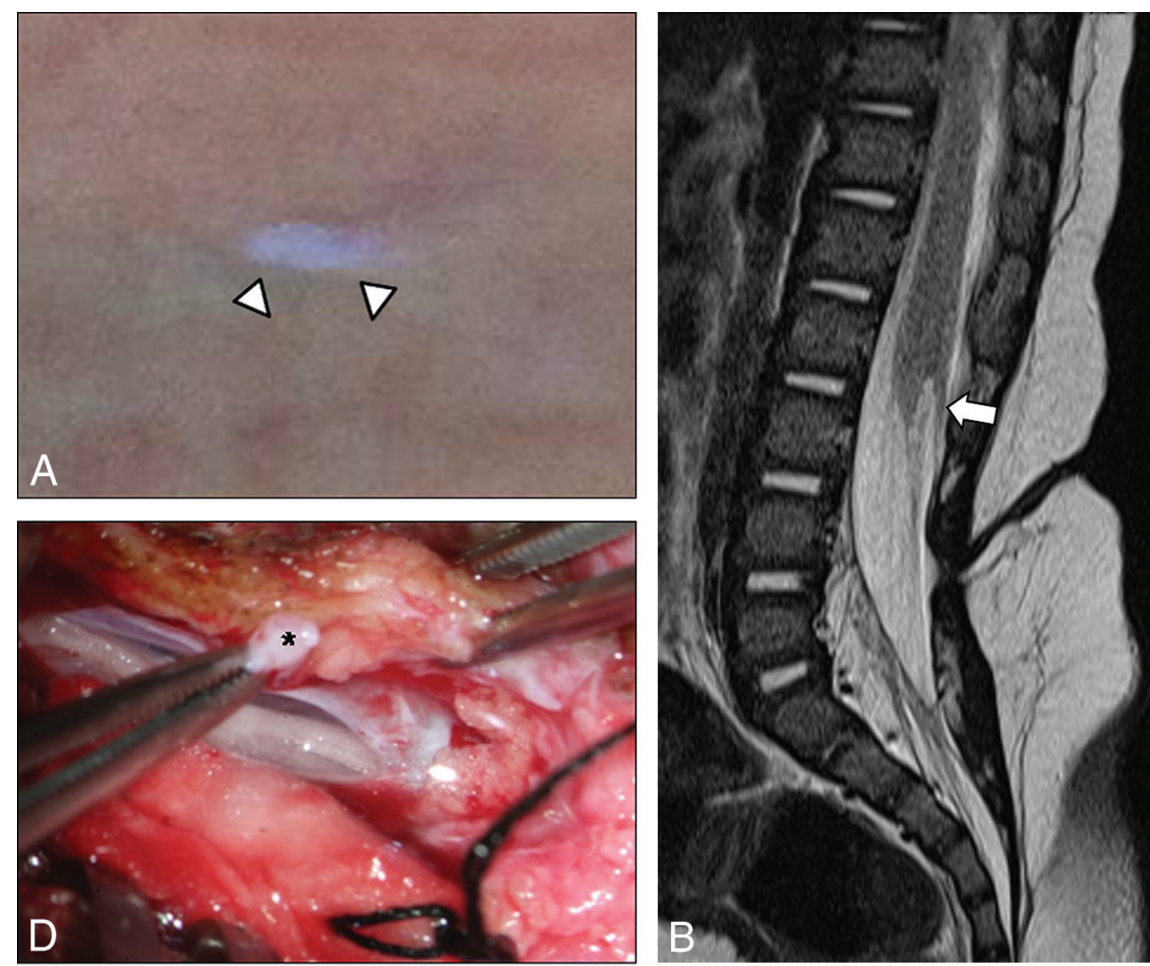

FIG 1. LDM in a 4-month-old girl who presented with a midline skin lesion in the lumbar area. A, Photograph shows a crater covered with pearly pale epithelium (arrowheads) described as a cigarette-burn mark. Sagittal (B) and axial (C) T2-weighted MR images show that the intraspinal tract (arrows) displaying a distinct hypointense round structure separate from the filum terminale or nerve roots is completely traceable in its entire course (classified as "entirely visible" tract). The attachment site of the tract is the spinal cord just above the conus medullaris. A low-lying conus medullaris and dorsal tenting of the spinal cord at the tract-cord union are seen (open arrow). $D$, Photograph obtained during the operation shows a thick tract (asterisk) adhering to the dorsal aspect of the spinal cord.

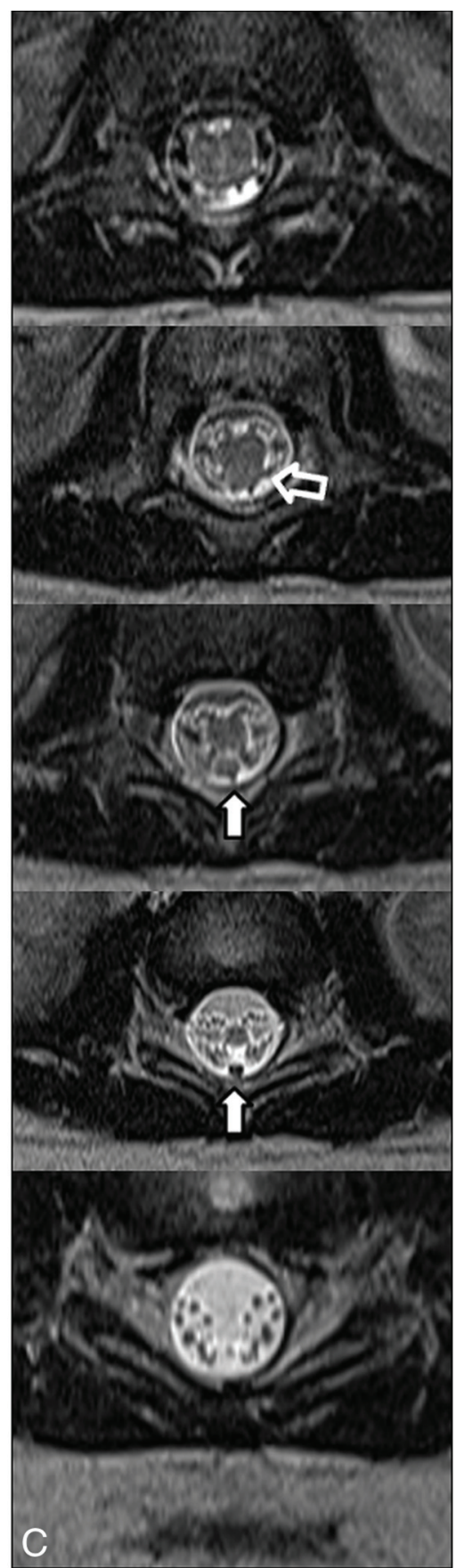

10 patients with CDS $(60 \%)$ were admitted with infectious manifestations: fever $(n=5)$, acute meningitis $(n=3)$, recurrent meningitis $(n=1)$, skin inflammation $(n=3)$, and purulent discharge from the pit $(n=4)$. Four of 10 patients with CDS (40\%) had abnormal neurologic signs and/or symptoms accompanied by an infectious complication, including 1 patient with quadriplegia and a neurogenic bladder. In patients with LDM, 2 of 12 (17\%) had neurologic deficits: mild lower extremity weakness with urinary dysfunction on urodynamic studies. There was no significant difference in neurologic deficits between the 2 groups $(P=.348)$.

The summary of the clinical findings in the LDM and CDS groups is presented in Table 1.

\section{MRI Findings}

Tract. The subcutaneous portions of the tracts in all cases of LDM and CDS were traceable in their entirety on MR imaging. The visibility of the tract in its intrathecal course was significantly different between the 2 groups $(P=.003)$. All intrathecal tracts of LDM were either entirely visible $(10 / 12,83 \%)$ or partially visible $(2 / 12,17 \%)$ (Figs 1 and 2), whereas 5 of 10 intrathecal tracts (50\%) were visible in CDS (entirely visible in 1 patient; partially visible in 4 patients). In 4 patients with CDS (40\%), intrathecal tracts were poorly visible because they were indistinguishable from intradural cystic lesions and smudgy heterogeneous lesions fully filling the intrathecal space (Fig 3). 

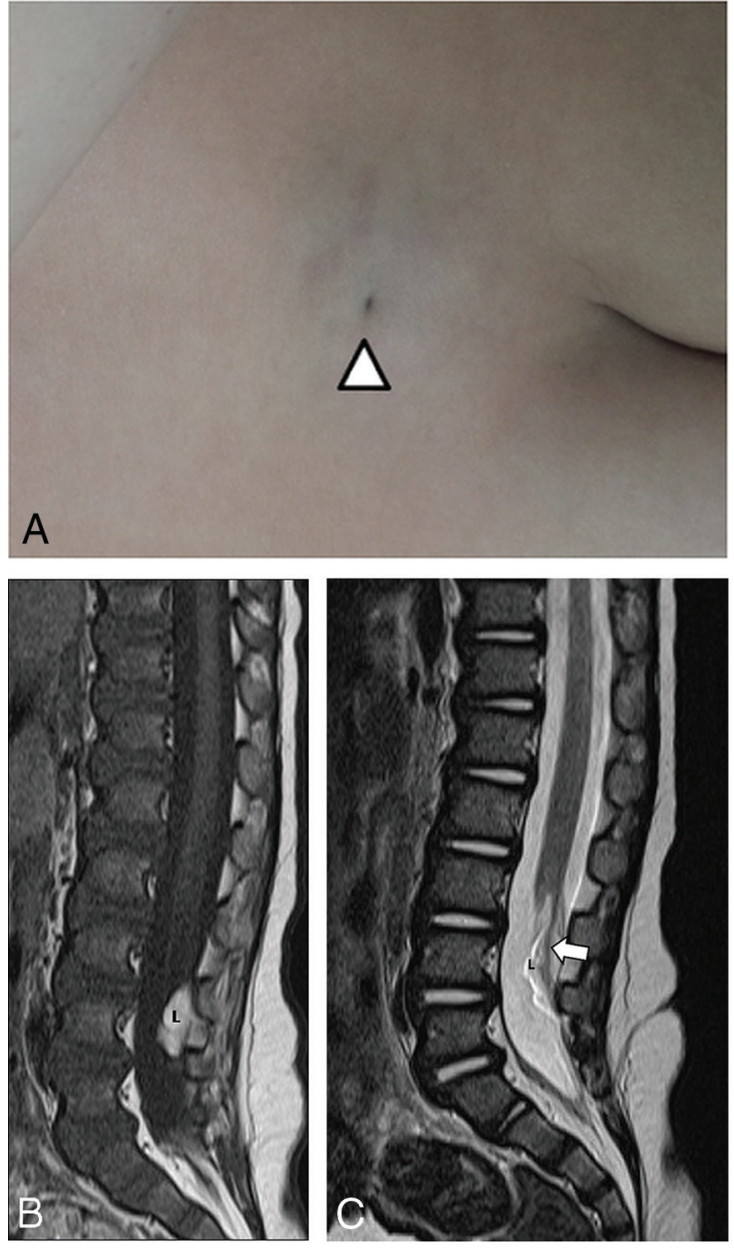

FIG 2. LDM in an 11-month-old girl with an intradural lipoma. $A$, Photograph shows a pinpoint pit (arrowhead) in the midline area of the lumbosacral region. T1-weighted $(B)$ and sagittal T2-weighted $(C)$ MR images show an entirely visible intrathecal tract (arrow) traversing the center of an intradural dorsal lipoma (L) and a low-lying conus medullaris. The attachment site of the tract is the spinal cord is just above the conus medullaris. $D$, Sequential axial T2-weighted MR images show dorsal tenting of the spinal cord (open arrow) and tract with low signal intensity (arrows).

Table 1: Comparison of LDM and CDS: clinical data

\begin{tabular}{lccc}
\hline & LDM $(\boldsymbol{n}=12)$ & CDS $(\boldsymbol{n}=10)$ & $P$ Value \\
\hline Male/female & $2: 10$ & $6: 4$ & .074 \\
Age $\left(\right.$ mo) at admission $^{\mathrm{a}}$ & $11 \pm 14.2(0.5-47)$ & $12.9 \pm 9(0.25-34)$ & .207 \\
Clinical presentation $^{\text {Skin abnormality }}$ & & & $<.0001$ \\
$\quad$ Skin-covered crater & $10(83 \%)$ & 0 & \\
$\quad$ Pit & $2(17 \%)$ & $10(100 \%)$ & \\
Infection $^{\text {b }}$ & 0 & $6(60 \%)$ & .003 \\
Neurologic deficit $^{\mathrm{b}}$ & $2(17 \%)$ & $4(40 \%)$ & .348 \\
\hline
\end{tabular}

${ }^{a}$ Data are mean value, with ranges in parentheses.

${ }^{\mathrm{b}}$ Data are number of patients, with percentages in parentheses.

In 1 patient with CDS, the tract was revealed to end in the dura mater at surgery and there was no tract in the intrathecal portion.

For attachment sites of the tract, a significant difference was found between the 2 groups $(P=.004)$. In all 12 patients with LDM, the attachment sites of the tracts were clearly identified as a

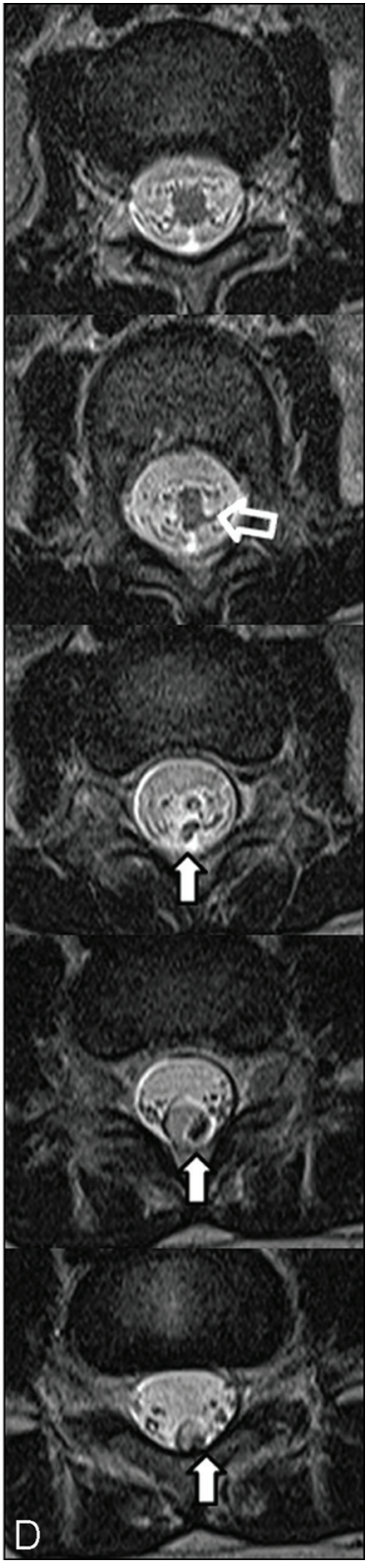

hypointense round structure adhering to the dorsal aspect of the spinal cord above the conus medullaris on MR imaging (Figs 1 and 2). In contrast, the attachment sites of the CDS tracts were varied and were not clearly visualized on MR imaging, even in patients with visible intrathecal tracts.

Spinal Cord. While a low-lying conus medullaris, indicating a tethered cord on MR imaging, was slightly more frequent in patients with $\operatorname{LDM}(9 / 12,75 \%)$ compared with those with CDS (6/10, $60 \%)$, the difference was not statistically significant $(P=.652)$. Neither patients with LDM nor those with CDS had a thickened filum terminale.

For the shape of the spinal cord, a significant difference was found between LDM and CDS $(P=.001)$. Ten of 12 patients with LDM (83\%) had dorsal tenting of the spinal cord at the tractcord union (Figs 1 and 2), whereas only 1 of 10 patients with CDS (10\%) had that appearance. An area of CSF collection within the spinal cord, representing a syringohydromyelia, was seen in 2 of 12 patients with LDM (17\%).

Intradural Lesions. For intradural lesions such as dermoid and epidermoid tumors, a significant difference was found $(P=.003)$ : dermoid and epidermoid tumors were present only in the CDS (6/10, 60\%; 5 epidermoid tumors and 1 dermoid tumor); none of the patients with LDM had these tumors. Epidermoid tumors had variable signal intensity, most commonly isointense with CSF but sometimes having a hypointense portion on T2-weighted images. Three epidermoid tumors appeared as ring-enhancing mass lesions nearly filling the entire intrathecal space with displacement of spinal cord or nerve roots. Two of these 3 were accompanied by spinal cord edema (Fig 3). One epidermoid and 1 dermoid tumor showed smudgy heterogeneous signal intensity intermingled in the nerve roots, with diffuse enhancement in the subarachnoid space and no distinct cystic mass. These aforementioned 5 lesions were infected, with the latter 2 ( 1 epidermoid and 1 dermoid) found to be ruptured at the operation. The remaining extramedullary epidermoid tumor was difficult to visualize on MR imaging: It was isointense with CSF and showed the minimal deviation of nerve roots with subtle rim enhancementand had presumably been infected. 

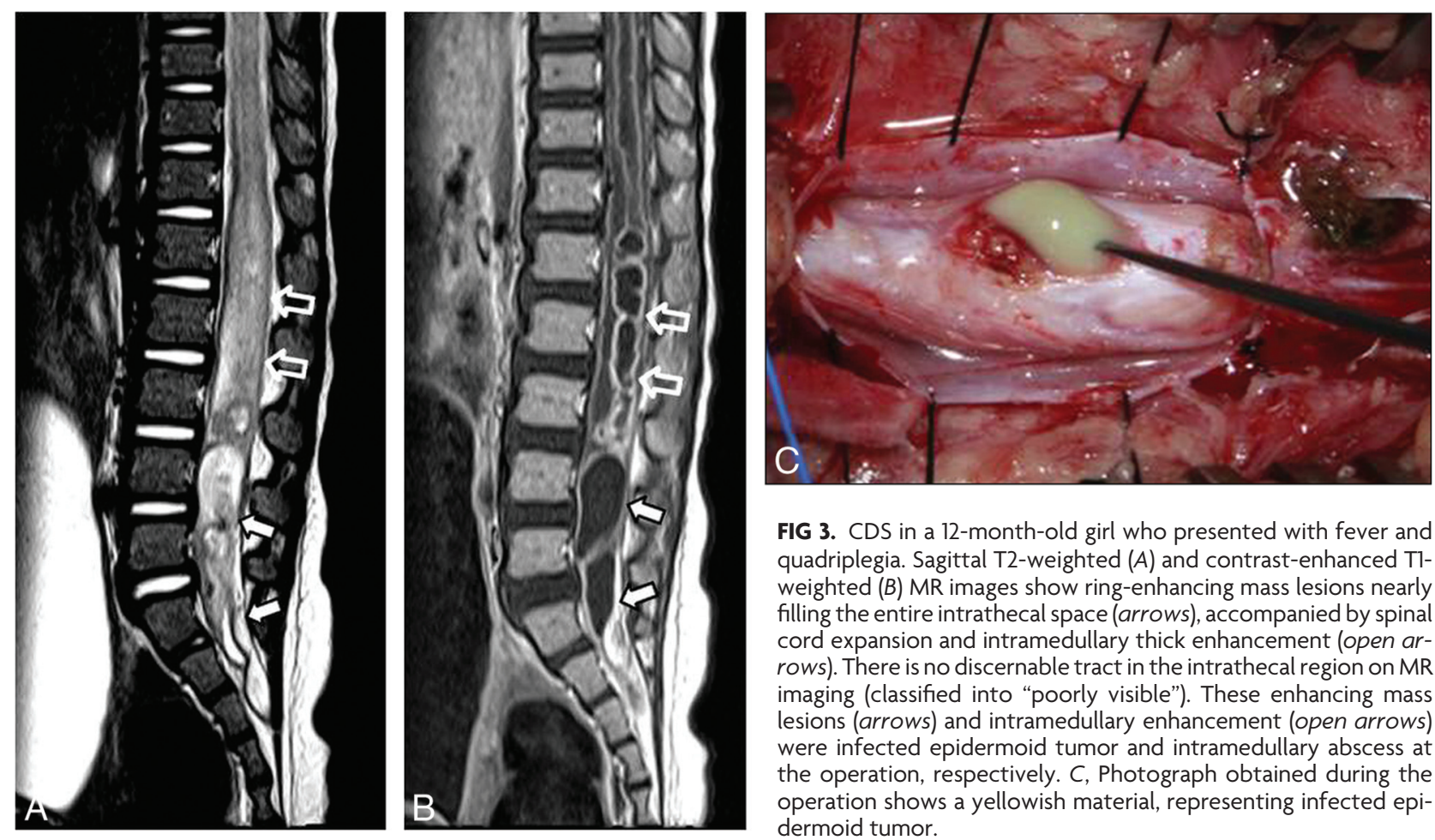

FIG 3. CDS in a 12-month-old girl who presented with fever and quadriplegia. Sagittal T2-weighted $(A)$ and contrast-enhanced T1weighted $(B)$ MR images show ring-enhancing mass lesions nearly filling the entire intrathecal space (arrows), accompanied by spinal cord expansion and intramedullary thick enhancement (open arrows). There is no discernable tract in the intrathecal region on MR imaging (classified into "poorly visible"). These enhancing mass lesions (arrows) and intramedullary enhancement (open arrows) were infected epidermoid tumor and intramedullary abscess at the operation, respectively. $C$, Photograph obtained during the operation shows a yellowish material, representing infected epidermoid tumor.

Table 2: Visibility of tract: MRI and operative findings ${ }^{a}$

\begin{tabular}{llccc}
\multicolumn{1}{c}{ Tract } & \multicolumn{1}{c}{ Visibility } & $\operatorname{LDM}(\boldsymbol{n}=12)$ & $\mathrm{CDS}(\boldsymbol{n}=10)$ & $\begin{array}{c}\boldsymbol{P} \\
\text { Value }\end{array}$ \\
\hline Subcutaneous & & $12(100 \%)$ & $10(100 \%)$ & - \\
Intrathecal $^{\mathrm{b}}$ & Entirely visible & $10(83 \%)$ & $1(10 \%)$ & .003 \\
& Partially visible & $2(17 \%)$ & $4(40 \%)$ & \\
& Poorly visible & $0(0 \%)$ & $4(40 \%)$ & \\
\hline
\end{tabular}

a Data are number of patients, with percentages in parentheses.

${ }^{b}$ Because the tract of 1 patient with CDS was revealed to end in the dura mater at the operation and there was no tract in the intrathecal area, only 9 CDS tracts were assessed with regard to visibility and attachment site in its intrathecal portion.

In patients with LDM with a low-lying conus medullaris, 2 were found to have intradural lipomas. Of these 2 cases, 1 had a tract traversing the center of a dorsal lipoma abutting the dura mater over its whole intrathecal course (Fig 2) and 1 had a fatlined tract not extending to the spinal cord. Intradural lipomas, running parallel to the intrathecal tract, were also identified in the 2 patients with CDS but did not extend the length of the tract.

Tables 2-5 summarize the MR imaging findings between the LDM and CDS groups compared with operative findings as a reference.

\section{DISCUSSION}

In this study, there was a significant difference in clinical and neuroimaging findings between LDM and CDS. The most common skin lesion of LDM was a crater covered with pearly pale epithelium described by previous reports as a "cigarette-burn mark." ${ }^{1,2,12}$ This skin lesion was not seen in our patients with CDS. Subjects with LDM had a relatively distinct intrathecal tract that was attached to the spinal cord just above the conus medullaris and showed dorsal tenting of the cord at the tract-cord union in most cases (83\%). LDM was not associated with an intradural infection or with dermoid or epidermoid tumors, unlike CDS. On the other hand, CDS had an indistinct intrathecal tract that ended in a variable depth and rarely showed a change in shape of the spinal cord $(10 \%)$. Intradural dermoid or epidermoid tumors were found in $60 \%$ of patients with CDS and were found to be infected at the operation.

These 2 entities have been described as having a different embryologic hypothesis and pathology. ${ }^{1,4,11,13}$ They both have been explained by abnormal neurulation during embryonic development. CDS may be the consequence of focal incomplete disjunction between the neural tube and cutaneous ectoderm, leading to a persistent epithelium-lined tract between the skin and central nervous system. ${ }^{7,11}$ However, some authors ${ }^{3,4}$ have postulated that LDM may be the result of the interposition of mesodermal cells between the neural tube and cutaneous ectoderm after separation of these 2 layers, consequently forming a solid tract composed of mesenchymal tissue with or without neural tissue.

These different embryonic errors and consequent distinctions in the histopathology may lead to differences in neuroimaging between the 2 groups. LDM has a solid tract composed of mainly attenuated fibrous tissue with variable portions of mesenchymal and neural elements—without a lumen — while CDS has a hollow tract lined by thin epithelium. ${ }^{1,3,11}$ Therefore, it could be postulated that visibility of the tract on MR imaging may be different between the 2 groups. In the present study, visibility of the tract was particularly different in its intrathecal portion surrounded by CSF. Most of the LDM tracts (83\%) were completely visible throughout their entire course and were seen as discrete hypointense tracts in their intrathecal portion, whereas only 1 CDS tract was entirely visible among 5 tracts detectable in the intrathecal space. Even the detectable intrathecal portions of the CDS tract appeared to be subtle and relatively thin compared with LDM on 
Table 3: Attachment site of tract: MRI and operative findings ${ }^{a}$

\begin{tabular}{|c|c|c|c|c|c|c|}
\hline \multirow[b]{2}{*}{ Tract } & \multirow[b]{2}{*}{ Attachment Site } & \multicolumn{2}{|c|}{$\operatorname{LDM}(n=12)$} & \multicolumn{2}{|c|}{$\operatorname{CDS}(n=10)$} & \multirow{2}{*}{$\begin{array}{c}P \\
\text { Value }\end{array}$} \\
\hline & & MRI & OP & MRI & OP & \\
\hline \multirow[t]{3}{*}{ Intrathecal $^{\mathrm{b}}$} & Conus medullaris & $12(100 \%)$ & $12(100 \%)$ & $2(20 \%)$ & $3(30 \%)$ & .004 \\
\hline & Filum terminale/nerve root & - & - & $2(20 \%)$ & $2(20 \%)$ & \\
\hline & $\begin{array}{l}\text { Dermoid/epidermoid tumor } \\
\text { Not available }^{c}\end{array}$ & - & - & $5(50 \%)$ & $4(40 \%)$ & \\
\hline $\begin{array}{l}\text { No extension into } \\
\text { the spinal canal }\end{array}$ & & - & - & $1(10 \%)$ & $1(10 \%)$ & \\
\hline
\end{tabular}

Note:-Op indicates operative findings.

${ }^{a}$ Data are number of patients, with percentages in parentheses.

${ }^{b}$ Because the tract of 1 patient with CDS was revealed to end in the dura mater at the operation and there was no tract

in the intrathecal area, only 9 CDS tracts were assessed with regard to visibility and attachment site in its intrathecal portion.

The attachment sites of the tracts could not be evaluated on MRI

Table 4: Configuration of spinal cord: MRI and operative findings ${ }^{a}$

\begin{tabular}{clrcc}
\hline & & $\begin{array}{c}\text { LDM } \\
(\boldsymbol{n}=12)\end{array}$ & $\begin{array}{c}\text { CDS } \\
(\boldsymbol{n}=10)\end{array}$ & $\begin{array}{c}\boldsymbol{P} \\
\text { Value }\end{array}$ \\
\hline $\begin{array}{c}\text { Level of the conus } \\
\text { medullaris }\end{array}$ & Normal & $3(25 \%)$ & $4(40 \%)$ & .652 \\
$\begin{array}{c}\text { Shape of the spinal } \\
\text { cord }\end{array}$ & Low-lying & $9(75 \%)$ & $6(60 \%)$ & \\
& Dorsal tenting & $10(83 \%)$ & $1(10 \%)$ & .001 \\
\hline
\end{tabular}

${ }^{a}$ Data are number of patients, with percentages in parentheses.

Table 5: Intradural lesions: MRI and operative findings ${ }^{a}$

\begin{tabular}{lccccc}
\hline $\begin{array}{c}\text { Associated Intradural } \\
\text { Lesions }\end{array}$ & MRI & OP & MRI & OP & $\begin{array}{c}P \\
\text { Value }\end{array}$ \\
\hline Dermoid-epidermoid & $0(0 \%)$ & $0(0 \%)$ & $5(50 \%)$ & $6(60 \%)$ & .003 \\
Lipoma & $2(17 \%)$ & $2(17 \%)$ & $2(20 \%)$ & $2(20 \%)$ & 1.000 \\
\hline
\end{tabular}

Note:-OP indicates operative findings.

${ }^{a}$ Data are number of patients, with percentages in parentheses.

MR imaging. The visibility of the CDS tract on MR imaging may also be influenced by the presence of a coexisting intraspinal infection as well as the innate histopathology of the tract itself. In this study, 4 CDS tracts were poorly visible due to infected intradural dermoid or epidermoid tumors fully filling the intrathecal space. These findings are consistent with some previous reports regarding the 2 groups. $1,6,11,14$

In terms of attachment site of the tract, there was a significant difference between the 2 groups in the present study: CDS tracts ended in varying structures, including dermoid or epidermoid tumors, while all LDM tracts were attached to the spinal cord above the conus medullaris. Although some investigators have mentioned that LDM tracts can also attach to other intraspinal structures such as the arachnoid membrane, dura mater, intradural dorsal lipoma, and filum terminale, ${ }^{3-5}$ our results were consistent with the cases presented by Pang et al. ${ }^{1}$

LDM $(10 / 12,83 \%)$ was significantly more likely than CDS $(1 / 10,10 \%)$ to be associated with a change in the shape of the spinal cord. The positive predictive value of this finding in the diagnosis of the LDM was 91\% (10/11). The change in spinal cord shape, referred to as dorsal tenting of the spinal cord or a trapezoid shape of the cord-tract union by Pang et al, ${ }^{1}$ can result from the tethering effect of the tract on the spinal cord where the tract joins it. A difference in the attachment site of the tract between the 2 groups may explain these results. However, only 1 of 3 patients with CDS with a tract attached to the spinal cord showed dorsal tenting of the spinal cord. Therefore, another factor may also influence the change in cord shape besides attachment of the tract to the cord. As mentioned above, LDM is a solid tract composed of dense mesenchymal tissue, while CDS is a hollow tract lined with thin epithelium. The higher density of the LDM tract may lead to a more obvious tethering effect on the spinal cord where the tract joins it. Furthermore, a syringohydromyelia near the cord-tract union, which disappeared after removal of the tract, was seen in only the patients with LDM (2/ $12,17 \%$ ) and was presumably caused by the tethering effect of the tract.

Several studies have reported that disability is related to spinal cord tethering in many patients with LDM. $^{1,3,5,15}$ On the other hand, CDS might rarely cause spinal cord tethering according to the report by Martinez-Lage et al, ${ }^{5}$ though other investigators have reported that CDS has a relatively higher rate of tethered cord, ranging from $57 \%$ to $79 \% .^{6,7,16} \mathrm{Al}$ though tethered cord syndrome is a clinical diagnosis, a tethered cord may be suggested by a low position of the conus medullaris seen on MR imaging. ${ }^{11,17-19}$ In the present study, the presence of a low-lying conus medullaris was not significantly different between the 2 groups, while it was slightly more frequent in patients with LDM (75\%) than in those with CDS (60\%). The development of cord tethering can be affected by the presence of associated lesions such as dysraphic malformations and dermoid and epidermoid tumors, as well as the tethering effect of the tract itself. ${ }^{20}$ In our patients with LDM, aside from the one with intradural lipoma, the cause of the low-lying conus medullaris could not be explained in any other way besides the tethering effect of the tract itself. In contrast, dermoid or epidermoid tumors filling the entire intrathecal space seemed to tether the cord in half of our patients with CDS with a low-lying conus medullaris. Therefore, we postulate that the higher density of the tract in LDM compared with CDS may more frequently cause spinal cord tethering in the absence of an associated intradural lesion.

Dermoid tumors contain skin appendages lined with an epithelium, and epidermoid tumors consist of epidermal elements of the skin. ${ }^{11}$ They commonly develop from congenital dermal-epidermal rests and could arise in the CDS as a consequence of desquamation of the tract lining, which is similar to the normal epidermis. ${ }^{6}$ In our study, a considerable number of patients with CDS (60\%) had dermoid or epidermoid tumors in the intraspinal space. Intraspinal-extramedullary dermoid or epidermoid tumors may be difficult to visualize and could be underestimated on MR imaging. ${ }^{1,14}$ However, we found that 5 of the 6 patients with CDS having dermoid or epidermoid tumors at the operation had either enhancing cystic masses or smudgy enhancing lesions without a distinct mass on MR imaging. The higher sensitivity in the detection of dermoid and epidermoid tumors in our results may be from an associated intraspinal infection: The 5 aforementioned patients with CDS were admitted to the hospital with acute infectious symptoms, and all were found to have infected extramedullary dermoid or epidermoid tumors at the operation.

The craters covered with pale epithelium described as a cigarette-burn mark by previous reports were a noteworthy feature in 
LDM. $^{1,2,12}$ These served as closed skin defects, unlike the skin lesion of CDS, thus not being associated with infectious complications. We think that this skin lesion can be useful in decisionmaking along with the aforementioned neuroimaging findings. Two patients with LDM had a pinpoint pit, which, surprisingly, contained microscopic foci of squamous epithelium at the subcutaneous course of the tracts, but not at the intrathecal course. As in the report by Pang et al, ${ }^{1}$ these may represent the concurrent presence of LDM and CDS sharing the same skin abnormality. We anticipate a further large study of associated dysraphic malformations of LDM.

There were several limitations in the present study. First, it was based on retrospective data collection, and patients with pathologic proof of a disease were necessarily enrolled. Second, the study population was small. Because LDM is a relatively unknown condition, it may have been misreported as another disease entity, including tethered spinal cord or CDS previously. This study can provide insight into CDS-mimicking lesions for radiologists. Further studies with a larger patient population are needed to confirm our findings.

\section{CONCLUSIONS}

LDM has a distinct intrathecal tract that attaches to the spinal cord above the conus medullaris and shows characteristic dorsal tenting of the cord at the tract-cord union. LDM is not associated with dermoid and epidermoid tumors. In patients with the aforementioned neuroimaging findings who have experienced no infectious complications since birth, the possibility of an LDM may be high. In addition, the presence of the characteristic skin lesion of LDM, referred to as the cigarette-burn mark, may be helpful in distinguishing it from CDS.

\section{REFERENCES}

1. Pang D, Zovickian J, Wong ST, et al. Limited dorsal myeloschisis: a not-so-rare form of primary neurulation defect. Childs Nerv Syst 2013;29:1459-84 CrossRef Medline

2. Pang D, Zovickian J, Oviedo A, et al. Limited dorsal myeloschisis: a distinctive clinicopathological entity. Neurosurgery 2010;67:155579; discussion 79-80 CrossRef Medline

3. van Aalst J, Beuls EA, Cornips EM, et al. The spinal dermal-sinus-like stalk. Childs Nerv Syst 2009;25:191-97 CrossRef Medline
4. De Vloo P, Lagae L, Sciot R, et al. Spinal dermal sinuses and dermal sinus-like stalks analysis of 14 cases with suggestions for embryologic mechanisms resulting in dermal sinus-like stalks. Eur J Paediatr Neurol 2013;17:575-84 CrossRef Medline

5. Martinez-Lage JF, Almagro MJ, Ferri-Ñiguez B, et al. Spinal dermal sinus and pseudo-dermal sinus tracts: two different entities. Childs Nerv Syst 2011;27:609-16 CrossRef Medline

6. Barkovich AJ, Edwards M, Cogen PH. MR evaluation of spinal dermal sinus tracts in children. AJNR Am J Neuroradiol 1991;12:123-29 Medline

7. Ackerman LL, Menezes AH. Spinal congenital dermal sinuses: a 30year experience. Pediatrics 2003;112:641-47 CrossRef Medline

8. Cornips EM, Weber JW, Vles JS, et al. Pseudo-dermal sinus tract or spinal dermal-sinus-like stalk? Childs Nerv Syst 2011;27:1189-91; author reply 93 CrossRef Medline

9. Tortori-Donati P, Rossi A, Cama A. Spinal dysraphism: a review of neuroradiological features with embryological correlations and proposal for a new classification. Neuroradiology 2000;42:471-91 CrossRef Medline

10. van Aalst J, Beuls EA, Cornips EM, et al. Anatomy and surgery of the infected dermal sinus of the lower spine. Childs Nerv Syst 2006;22: 1307-15 CrossRef Medline

11. Schwartz E, Barkovich J. Congenital anomalies of the spine. In: Barkovich J, Raybaud C, eds. Pediatric Neuroimaging. 5th ed. Philadelphia: Lippincott Williams \& Wilkins; 2012

12. Schropp C, Sörensen N, Collmann H, et al. Cutaneous lesions in occult spinal dysraphism: correlation with intraspinal findings. Childs Nerv Syst 2006;22:125-31 CrossRef Medline

13. Rajpal S, Salamat MS, Tubbs RS, et al. Tethering tracts in spina bifida occulta: revisiting an established nomenclature. J Neurosurg Spine 2007;7:315-22 CrossRef Medline

14. Tisdall MM, Hayward RD, Thompson DN. Congenital spinal dermal tract: how accurate is clinical and radiological evaluation? J Neurosurg Pediatr 2015;15:651-56 CrossRef Medline

15. Kaffenberger DA, Heinz ER, Oakes JW, et al. Meningocele manqué: radiologic findings with clinical correlation. AJNR Am J Neuroradiol 1992;13:1083-88 Medline

16. Radmanesh F, Nejat F, El Khashab M. Dermal sinus tract of the spine. Childs Nerv Syst 2010;26:349-57 CrossRef Medline

17. Jones BV. Tethered spinal cord. In: Donnelly LF, ed. Diagnostic Imaging Pediatrics. 2nd ed. Salt Lake City, Utah: Amirsys; 2012:12

18. Bui CJ, Tubbs RS, Oakes WJ. Tethered cord syndrome in children: a review. Neurosurg Focus 2007;23:E2 Medline

19. Warder DE, Oakes WJ. Tethered cord syndrome and the conus in a normal position. Neurosurgery 1993;33:374-78 CrossRef Medline

20. Geyik M, Alptekin M, Erkutlu I, et al. Tethered cord syndrome in children: a single-center experience with 162 patients. Childs Nerv Syst 2015;31:1559-63 CrossRef Medline 